\title{
Article \\ Citrus Pomace Biomass as a Source of Pectin and Lignocellulose Fibers: From Waste to Upgraded Biocomposites for Mulching Applications
}

\author{
Domenico Zannini, Giovanni Dal Poggetto (D, Mario Malinconico, Gabriella Santagata and Barbara Immirzi *
}

check for updates

Citation: Zannini, D.; Dal Poggetto, G.; Malinconico, M.; Santagata, G.; Immirzi, B. Citrus Pomace Biomass as a Source of Pectin and Lignocellulose Fibers: From Waste to Upgraded Biocomposites for Mulching Applications. Polymers 2021, 13, 1280. https://doi.org/10.3390/ polym 13081280

Academic Editor:

Łukasz Klapiszewski

Received: 24 March 2021

Accepted: 13 April 2021

Published: 14 April 2021

Publisher's Note: MDPI stays neutra with regard to jurisdictional claims in published maps and institutional affiliations.

Copyright: (c) 2021 by the authors. Licensee MDPI, Basel, Switzerland. This article is an open access article distributed under the terms and conditions of the Creative Commons Attribution (CC BY) license (https:// creativecommons.org/licenses/by/ $4.0 /)$.
Institute of Polymers, Composites and Biomaterials, National Research Council, Via Campi Flegrei 34, 80078 Pozzuoli, Italy; domenico.zannini@ipcb.cnr.it (D.Z.); giovanni.dalpoggetto@ipcb.cnr.it (G.D.P.); mario.malinconico@ipcb.cnr.it (M.M.); gabriella.santagata@ipcb.cnr.it (G.S.)

* Correspondence: barbara.immiriz@ipcb.cnr.it

Abstract: Citrus pomace derived from the industrial processing of juice and essential oils mostly consists of pectin, cellulose, hemicellulose, and simple sugars. In this work, citrus pomace waste from an agricultural company in South Italy was used as source of pectin. The extraction conditions of the polysaccharide were optimized using a suitable combination of time and a concentration of a mild organic solvent, such as acetic acid; thus recovering high $\mathrm{M}_{\mathrm{w}}$ pectin and bioactive molecules (flavonoids and polyphenols). The pectin was structurally (GPC, FTIR), morphologically (SEM), thermally (TGA/DTG), and mechanically characterized, while bioactive molecules were separated and the total phenolic content (TPC) and total flavonoids content (TFC) were evaluated. With the aim to develop novel biocomposite-based materials, the pectin extracted from citrus waste was reinforced with different amounts of lignocellulose fractions also recovered from citrus waste after polysaccharide extraction, according to a "zero waste" circular economy approach. The prepared biocomposites were morphologically and mechanically characterized to be used as biodegradable mulching systems for crop protection. Thus, the citrus waste biomass was recovered, fractionated into its main raw materials, and these were recombined to develop novel upgraded biocomposites for mulching applications, by means of a cost-effective and eco-sustainable approach.

Keywords: citrus pomace waste; pectin; circular economy approach; green extraction; biocomposites; mulching application

\section{Introduction}

Citrus is the one of the largest and most popular commercially grown fruit crops across the world. Annually, it is estimated that 33\% of the total global citrus harvest is used for juice and essential oil production [1]. In Italy alone, about 3 million tons of citrus fruit are produced annually: mainly lemons, oranges, bergamot, and clementine. The citrus processing industries produce huge amounts of waste: over 40 million tons worldwide, which plays a key role in global environment impact, since the huge organic and water load of landfilled biomass leads to the formation of greenhouse gases and microbial contamination during bulk decomposition [2]. A valid eco-sustainable alternative to citrus waste landfilling is the exploitation of the biomass as a source of high added value compounds and macromolecules [3]. Actually, there is an emerging interest in using agricultural and food processing waste as a source of bioactive molecules for functional food products or as active pharmaceutical compounds [4]. It is suffice it to say that the reuse of waste or by-products in the food industry can increase economic value, provide environmental benefits, and better highlight eco-sustainability [5-7].

All the transformation processes used in the citrus industry give rise to three main products: juice, essential oil, and the residual pulp fraction, whose percentages are approximately $35-45 \%, 0.2-0.5 \%$, and 55-65\%, respectively. Actually, more than a waste, the pulp 
recovered after juice and oil extraction can be considered a processing by-product that is a source of active compounds, such as flavonoids and d-limonene, macromolecules, such as pectins and simple sugars, lignocellulose peel fibers, seed oils, and ethyl alcohol, which can be reintegrated and reused as secondary upgraded raw materials in the agro-food production chain [8-13].

Among them, pectin represents $45 \%$ of the total citrus waste by weight, together with soluble sugar, cellulose, and hemicellulose [14].

Pectin is a natural constituent of all terrestrial plants that is particularly abundant in the primary cell walls of fruit and vegetable. The chemical composition and structure of pectin is very complex and depends on the source, extraction methods, plants, storage, and maturity of the raw plant source. Nevertheless, it is generally accepted that the pectin structure consists of heterogeneous polysaccharides with three main structural domains covalently linked one to another, the homogalacturonan, and the highly branched rhamnogalacturonans regions [15-22]. Pectins are categorized according to their degree of esterification or methoxylation (DM), i.e., the percentage of carboxyl groups esterified with methanol. Pectins with a DM > 50\% are high-methoxyl pectins (HMP); those with a $\mathrm{DM}<50 \%$ are low-methoxyl pectins (LMP) [23]. For instance, high-methoxyl pectins form a gel when they are heated in low $\mathrm{pH}$ (2-3.5) water solutions containing a high concentration of sugars (about 55-75\%). Low-methoxy pectins form partly shear reversible gels in the presence of calcium ions. Hence, the esterification degree and the structural features of pectin, like molecular weight, are responsible for the functional properties of pectin [24,25]. Commercially, both citrus and apple pectins are often used as preservative, gelling, and thickening agents in the food processing industry because of their high DM and molecular weight [26]. The gelling, binding, biocompability, and nontoxic properties of pectin make it a promising biopolymer for biomedical and pharmaceutical applications [27].

Frequently, pectin is extracted from citrus peels and apple pomace using the acid extraction technique. Acids are highly effective at solubilizing and stabilizing the pectin that is tightly bound in the cell wall, making them the most effective extracting agents. Typically, industrial pectin production is implemented using acidified water with hydrochloric, nitric, sulphuric acid, or organic acids at $\mathrm{pH} 1.0-3.0$, high temperatures (70-90 ${ }^{\circ} \mathrm{C}$ ), and extraction times of 1-12 h, depending on the desired properties of the pectin [28].

However, it is widely reported that the use of strong acids could result in pectin depolymerization and de-esterification, as well as disposal and environmental issues due to their corrosive and toxic nature [29]. Therefore, the experimental extraction conditions (temperature, extraction acid, time, and $\mathrm{pH}$ ) should be carefully controlled to achieve the desired pectin quality and yield [30].

In this paper, pectin was extracted from citrus pomace biomass using low concentrations of a mild organic acid, such as acetic acid. This choice was driven by the intended agricultural application of pectin. In fact, the author partnership has a long-standing expertise in developing biodegradable mulching films and biocomposites based on the water solutions of polysaccharides and cellulose fibers. The solutions are directly sprayable onto the soil and are able to form a protective geomembrane against the growth of spontaneous weeds that affect crop production. At the end of the cultivation period, the geomembranes can be buried into the soil where they are biodegraded by bacterial flora. As an example, sodium alginate water solutions, glycerol as a plasticizer, and cellulose fibers as a reinforcing agent have been used as mulching materials for strawberry crop production under greenhouse conditions [31]. Another mulching application concerns the use of chitosan as a biopolymer matrix dissolved in an acetic acid solution at $3 \% v / v$. In fact, acetic acid is an admitted substance in agronomic practices, being widely used as a natural herbicide [32]. Moreover, chitosan has been reported to possess antifungal and antibacterial activity and it has been shown to be effective in soil amendment, providing many benefits to different plant species by reducing pathogen attacks and infection [33]. The use of chitosan as a protective mulching geomembrane was demonstrated by the authors. It can form water stable films on the soil that are able to protect the cultivation crops from spontaneous 
weeds growth by exploiting local and systemic crop defense responses [34,35]. In their previous studies, the authors found that the use of $3 \% v / v$ of acetic acid in water solution represented a good compromise to perfectly dissolve chitosan without compromising its depolymerization.

In this paper, the same concentration of acetic acid was used to extract pectin from citrus waste biomass and then redissolve it so it could be sprayed on the soil. With the aim of reinforcing the geomembrane, lignocellulose fractions recovered from the same citrus biomass after pectin extraction were added. As far as we know, there is no literature data concerning the development of biocomposites based systems in which both the polymer and fibrous dispersed phase are derived from the same biomass. Specifically, from the pulp, pectin was extracted and separated from the solid fraction represented by fibers; pectin and fibers were then recombined in functional biocomposites. This novel approach could be framed in the context of the circular economy, as it provides the recovery of biomass, separation into its components, and their subsequent recombination in an upgraded form of secondary raw materials; thus, achieving an environmentally sustainable and low-cost closure following the zero-waste circular economy route [36]. In this paper, high molecular weight pectin was extracted in mild conditions from citrus waste biomass. The biopolymer was structurally (Gel Permeation Chromatography, GPC), (Fourier Transform Infrared, FTIR), morphologically (Scanning Electron Microscopy, SEM), thermally (Thermal Gravimetrical Analysis/Derivative Thermogravimetry, TGA/DTG), and mechanically characterized; from the citrus pulp, bioactive molecules were separated and the total phenolic content (TPC) and total flavonoids content (TFC) were evaluated. With the aim to develop novel biocomposite-based materials to be sprayed on the soil as a mulching geomembrane, the fiber residues obtained after pectin and biomolecule extraction were recovered and added to the pectin solutions. Preliminary morphological and mechanical characterizations of the biocomposites were performed in order to evaluate their potentiality as biodegradable mulching films.

\section{Materials and Methods}

\subsection{Material and Chemicals}

Citrus waste was supplied by Università Mediterranea of Reggio Calabria (Reggio Calabria, Italy), with a moisture content of about $15 \%$ by weight. Analytical-grade glacial acetic acid (HAc), isopropanol, ethanol, acetone, bicarbonate sodium $\left(\mathrm{NaHCO}_{3}\right)$ Folin-Ciocalteau reagent, aluminum trichloride $\left(\mathrm{AlCl}_{3}\right)$, sodium nitrite $\left(\mathrm{NaNO}_{2}\right)$, sodium hydroxide $(\mathrm{NaOH})$, and hydrochloric acid $(\mathrm{HCl}, 36 \%)$ were purchase from Sigma-Aldrich, Merck Group (Saint Louis, MI, USA). Citrus Pectin Classic CU 701 (PEC) was kindly supplied by Herbstreit \& Fox (Neuenbürg, Germany), with a degree of esterification of $34 \%$ and a galacturonic acid content of $86 \%$.

\subsection{Extraction and Purification of Pectin from Citrus Waste}

In a typical extraction, $20 \mathrm{~g}$ of powder citrus waste were dispersed in $200 \mathrm{~mL}$ of a solution of $3 \%(v / v)$ HAc $(\mathrm{pH}=2.6)$. The pectin extraction was performed at $90-100{ }^{\circ} \mathrm{C}$ for $6 \mathrm{~h}$ under magnetic stirrer. Afterwards, the suspension obtained was rapidly cooled to room temperature, and filtered to separate the liquid extract from the insoluble fraction. In order to definitively remove the solid residues, the liquid extract was centrifuged for $40-50$ min at $10,000 \times g$ at $4{ }^{\circ} \mathrm{C}$.

Once the liquid fraction was recovered, the pectin was precipitated with an excess of isopropanol (a twice the volume with respect to the liquid extract volume) and filtrated on paper filter.

The pectin was washed with ethanol and put into a vacuum oven at $60{ }^{\circ} \mathrm{C}$ until reaching a constant weight. Finally, the percentage yield of the pectin was determined through the following equation (Equation (1)):

$$
\text { Yield }(\%)=\left(\frac{a}{b}\right) \times 100
$$


where $a$ corresponds to the quantity of pectin obtained from the extraction, and $b$ corresponds to the initial amount of powder citrus waste $[37,38]$. The percentage yield of the extracted pectin was around $24 \%$.

The alcoholic fractions of isopropanol and ethanol were mixed and evaporated using a rotavapor instrument; the obtained powder was analyzed to evaluate the total phenol (TPC) and flavonoid contents (TFC).

The lignocellulose fraction, recovered after the pectin extraction, was washed with a $\mathrm{NaHCO}_{3}(3 \%$ wt.) solution until neutrality and dried under vacuum. Finally, it was ground through a mill and sieved then recombined with the pectin for the preparation of the biocomposites.

\subsection{Pectin Film and Biocomposites}

The amount of the dried pectin recovered from $10 \mathrm{~mL}$ of the liquid extract was about $0.30 \mathrm{~g}$. Firstly, a film of purified pectin (Purified PEC), used as control, was prepared by dissolving $1.00 \mathrm{~g}$ of pectin in $35 \mathrm{~mL}$ of $3 \% \mathrm{v} / \mathrm{v}$ of acetic acid water solution. The solution was poured in a Petri dish and allowed to dry at room temperature under a ventilated hood. In order to follow a cost-effective approach, the other films of pectin were prepared by casting $35 \mathrm{~mL}$ of liquid extract containing about $1.00 \mathrm{~g}$ of pectin. In order to follow a holistic approach by recombining the pectin and the fiber residual fraction to obtain biocomposites, $0.15 \mathrm{~g}, 0.25 \mathrm{~g}$, and $0.35 \mathrm{~g}$ of lignocellulose fibers, recovered after pectin extraction, were added to the polymer matrix and casted on Petri dish and dried as previously described. Thus, biocomposites, named PEC-15, PEC-25, PEC-35, respectively, were obtained.

The film and biocomposite compositions and their identification codes are reported in Table 1.

Table 1. Pectin-based film and biocomposite compositions and their identification codes.

\begin{tabular}{ccc}
\hline Identification Code & $\begin{array}{c}\text { Pectin (PEC) } \\
(\mathbf{g})\end{array}$ & $\begin{array}{c}\text { Residue } \\
\text { (g) }\end{array}$ \\
\hline Purified PEC & 1 & - \\
PEC & 1 & - \\
PEC-15 & 1 & 0.15 \\
PEC-25 & 1 & 0.25 \\
PEC-35 & 1 & 0.35 \\
\hline
\end{tabular}

\subsection{Characterizations Methods}

\subsubsection{Gel Permeation Chromatography (GPC)}

Gel permeation chromatography was performed on pectin extracted at different times or acidic contents. The analysis was carried out using a GPC Max Viscotek (Malvern, UK) Phenomenex (Torrance, CA, USA) system equipped with a TDA 305 detector (Refractive Index, Low Angle Light Scattering, Right Angle Light Scattering and Viscometer) and UV detector. We used a pre-column TSK PW $\mathrm{XL}_{\mathrm{L}}$ and TSK Gel GMPWXL. All the samples were dissolved at $2 \mathrm{mg} / \mathrm{mL}$ concentration and eluted in MilliQ water containing $0.2 \% \mathrm{NaN}_{3}$ and $0.1 \mathrm{M} \mathrm{NaNO}_{3}$. After complete dissolution, samples were filtered through membranes of $0.22 \mu \mathrm{m}$ porosity. The injection volume was $100 \mu \mathrm{L}$, and the flow rate was $0.6 \mathrm{~mL} / \mathrm{min}$. The chosen method of analysis was triple point, calibrated with a PEO standard, provided by Viscotek, with a narrow molecular weight distribution. The measurements, performed at $40{ }^{\circ} \mathrm{C}$ according to the temperatures of the columns and detectors, ran for $60 \mathrm{~min}$ in triplicate.

\subsubsection{Degree of Methoxylation (DM) Measurement}

The DM value of extracted pectins was obtained using a titrimetric method [39]. First, $2 \mathrm{~mL}$ of ethanol was added to the $200 \mathrm{mg}$ sample with $20 \mathrm{~mL}$ of distilled water. It was mixed thoroughly until complete dissolution. Two drops of phenolphthalein were added to the mixture and the mixture was titrated with $\mathrm{NaOH}$ solution $(0.1 \mathrm{M})$ until it 
appeared pale pink. The volume of added $\mathrm{NaOH}$ after the titration was noted as $\mathrm{V}_{1}$. Afterward, the solution was mixed with $10 \mathrm{~mL}$ of $\mathrm{NaOH}$. The mixture was shaken for $1 \mathrm{~h}$ at room temperature. Then, $10 \mathrm{~mL}$ of $\mathrm{HCl}$ solution $(0.1 \mathrm{M})$ was added and the mixture was stirred until the pink color disappeared. The solution was titrated again with $\mathrm{NaOH}$ solution $\left(\mathrm{V}_{2}\right)$. The DM value of pectins was calculated according to the following equation (Equation (2)), all the measurements were performed in triplicate, and the results are reported as averaged values.

$$
\mathrm{DM}(\%)=\left[\mathrm{V}_{2} /\left(\mathrm{V}_{2}+\mathrm{V}_{1}\right)\right] \times 100
$$

\subsubsection{Attenuated Total Reflection Fourier Transform Infrared Spectroscopy (FTIR-ATR)}

FTIR analysis was recorded in an Attenuated Total Reflection near FTIR-ATR (ATR modality) on powder pectins using a Perkin-Elmer Spectrum 100 (Waltham, MA, USA). The samples were dried under vacuum for $24 \mathrm{~h}$ at $60^{\circ} \mathrm{C}$ to remove water traces. Spectra were recorded as an average of 16 scans (range: $4000-650 \mathrm{~cm}^{-1}$, resolution: $4 \mathrm{~cm}^{-1}$ ).

\subsubsection{Total Phenolic Content (TPC)}

Determination of the TPC was performed according to [40]. Briefly, $125 \mu \mathrm{L}$ of sample solution $\left(2 \% w / v\right.$ dry mass of alcoholic liquid fraction in $\left.\mathrm{H}_{2} \mathrm{O}\right)$ were mixed with $125 \mu \mathrm{L}$ of Folin-Ciocalteau reagent. After $6 \mathrm{~min}$ of incubation, $1.25 \mathrm{~mL}$ of aqueous solution $7 \% \mathrm{w} / \mathrm{v}$ $\mathrm{NaHCO}_{3}$ were added and the final solution was left at room temperature for $90 \mathrm{~min}$ in the dark. After this time, the absorbance was measured at $760 \mathrm{~nm}$ using a UV-Vis spectrophotometer $(\mathrm{V}-570$ Jasco, double beam system with a single monochromator, Easton, Van Nuys, LA, USA). To calculate TCP, the calibration curve of catechin $(0-600 \mu \mathrm{g})$ was calculated. The result, in duplicate, was expressed as mg of catechin equivalents (CE) per g of sample dry weight (mg CE/g).

\subsubsection{Total Flavonoids Content (TFC)}

TFC was evaluated according to [41]. A sample solution of $0.5 \mathrm{~mL}(2 \% w / v$ dry mass of alcoholic liquid fraction in $\mathrm{H}_{2} \mathrm{O}$ ) was mixed with $2 \mathrm{~mL}$ of $\mathrm{H}_{2} \mathrm{O}$ and $0.15 \mathrm{~mL}$ of $5 \% w / v \mathrm{NaNO}_{2}$ and final solution was incubated at room temperature for $6 \mathrm{~min}$. Then, $0.15 \mathrm{~mL}$ of $10 \% w / v \mathrm{AlCl}_{3}$ were added and left at room temperature for $6 \mathrm{~min}$. Finally, $2 \mathrm{~mL}$ of $4 \% w / v \mathrm{NaOH}$ and $0.7 \mathrm{~mL}$ of $\mathrm{H}_{2} \mathrm{O}$ were added and the mixture was left at room temperature for supplementary $15 \mathrm{~min}$. The absorbance was measured at $510 \mathrm{~nm}$ using a UV-Vis spectrophotometer ( $\mathrm{V}-570 \mathrm{Jasco}$, double beam system with a single monochromator, Easton, Van Nuys, LA, USA), the calibration curve was obtained from the known concentrations of catechin $(0-600 \mu \mathrm{g})$, and the TFC was expressed as mg of catechin equivalents per $\mathrm{g}$ of sample dry weight $(\mathrm{mg} \mathrm{CE} / \mathrm{g})$. Measurements were performed in duplicate.

\subsubsection{Thermogravimetric Analysis (TGA)}

Thermogravimetrical analysis of pectins and lignocellulose residue were performed using a thermogravimetric analyzer TGA/DTG Perkin-Elmer PyrisDiamond, equipped with gas station. A 3-4 mg sample was placed in an open ceramic crucible and heated from $25^{\circ} \mathrm{C}$ to $600{ }^{\circ} \mathrm{C}$ at a speed rate of $10^{\circ} \mathrm{C} / \mathrm{min}$, under nitrogen at $30 \mathrm{~mL} / \mathrm{min}$. Before testing, samples were kept under vacuum at $60^{\circ} \mathrm{C}$ for $24 \mathrm{~h}$.

\subsubsection{Mechanical Tests: Tensile Test and Puncture Test}

In order to simulate the natural pressure exerted by plants against the films, two different mechanical tests were performed: the tensile test and the puncture test, which is an empiric test previously used by [31]. All the mechanical analyses were performed on six specimens, previously conditioned at room temperature and at air relative humidity equal to $50 \%$. Tensile tests were carried out by a dynamometer model 4301, Instron (Canton, OH, USA) equipped with a load cell of $1 \mathrm{kN}$. The measurements were performed on dumbbell-shaped films. The width and the length of investigated films were 4 and $28 \mathrm{~mm}$, 
respectively, while the thickness of each film was measured using a digital micrometer (IP65 Mitutoyo, Kawasaki, Japan). The values were reported as the mean value of three different points measurements as the average value $(0.1 \pm 0.3 \mathrm{~mm})$. All the measurements were carried out at $25{ }^{\circ} \mathrm{C}$ and $50 \%$ relative humidity (RH), at a crosshead rate of $2 \mathrm{~mm} / \mathrm{min}$. Young's modulus, stress, and strain at break points were determined. The puncture test consisted in penetrating the specimens until the film was lacerated [31,42]. More specifically, the samples to be tested, opportunely cut with a $40 \mathrm{~mm}$ circular-section punch cutter, were trapped in cups fixed on the inferior traverse of the INSTRON instrument. They underwent the action of a force exerted by a spherical dart linked to a steel rod fixed on the upper traverse of the apparatus; the dart, moving down at a fixed rate of $2 \mathrm{~mm} / \mathrm{min}$, penetrated the sample until the rupture of the film. The applied load as a function of the displacement was recorded; the parameters obtained were normalized with respect to $1 / 2$ of the area of the sphere and with respect to an estimated value of the displacement of $10 \mathrm{~mm}$.

\subsubsection{Scanning Electron Microscope (SEM)}

Morphological analysis of powder pectins, film, and biocomposites were performed by means of a scanning electron microscope (SEM) (Quanta 200 FEG, 338 FEI, Eindhoven, The Netherlands), on powder samples. Surfaces were coated with a homogeneous layer $(18 \pm 0.2 \mathrm{~nm})$ of Au and Pd alloy by means of a sputtering device (MED 020, Bal-Tec AG, Tucson, AZ, USA). The micrographs were performed at room temperature, in high vacuum mode. By means of energy dispersive X-ray spectroscopy (EDS), it was possible to perform the chemical analysis of selected microscopic regions. EDS was performed in the SEM by means of an Oxford Inca Energy 250 System equipped with an INCAx-act LN2-free detector, using an accelerating voltage of $20.0 \mathrm{kV}$.

\section{Results}

Typically, industrial pectin production is performed by means of acid extraction methods, using hydrochloric, nitric, sulphuric acid, or organic acids at $\mathrm{pH}$ 1.0-3.0, high temperatures $\left(70-90{ }^{\circ} \mathrm{C}\right)$, and extraction times of $1-12 \mathrm{~h}$, depending on the desired properties of the pectin. However, the use of strong acids can induce pectin depolymerization, which affects its final properties.

In this paper, the use of acetic acid could allow pectin extraction from citrus waste without affecting its structural and functional properties. Several concentrations of acid and different extraction times were evaluated in order to reach the best compromise of processing parameters and pectin properties. On the basis of previous analyses performed by the authors on other pectin sources (results of which are not the subject of this manuscript), preliminary experiments on citrus biomass were performed using a high concentration of acetic acid solutions, specifically $9 \% v / v$ of acetic acid for 2,4 , and $6 \mathrm{~h}$. As a result, the extraction yield increased: from $16.4 \%$ after $2 \mathrm{~h}$ to $23.7 \%$ after $6 \mathrm{~h}$ of treatment. However, the methoxylation degree decreased [43]. In literature, it is reported that the demethoxylation process mainly occurs at basic $\mathrm{pH}$ [44]. However, Fraeye et al. [45] demonstrated that for a $\mathrm{pH}$ lower than 3, DM decreases due to acid catalyzed demethoxylation. In the tested samples, the high concentration of HAc (PEC 9\%HAc) combined with the high extraction temperature and prolonged times synergically acted to decrease the DM. For this reason, the acid concentration was reduced to $3 \% v / v$. The choice was suggested from the application point of view. As previously stated, the authors have corroborated experience in mulching geomembrane development using polysaccharide water solutions containing $3 \% v / v$ of acetic acid [31]. The lower concentration of acid prevented the polysaccharide dissolution, while higher concentrations of acid negatively affected the results of the tests, since the acetic acid did not provide a suitable selective action as a herbicide; as a result, the crop growth and quality were seriously impaired (data will be published in an upcoming paper in collaboration with an Italian agronomic partnership). Effectively, according to the 
results reported in Table 2, the use of a lower concentration of acid and an average time of $6 \mathrm{~h}$ produced suitable, efficient, and more interesting values for both yield and DM.

Table 2. Percentage of yield and degree of methoxylation (DM) of pectin as a function of time (h) and acetic acid concentration (\%).

\begin{tabular}{ccccc}
\hline Data/Samples & PEC-2h-9\% & PEC-4h-9\% & PEC-6h-9\% & PEC-6h-3\% \\
\hline Yield (\%) & $16.4 \pm 3.4$ & $20.3 \pm 2.2$ & $23.7 \pm 1.8$ & $24.1 \pm 2.6$ \\
DM (\%) & $70.6 \pm 3.2$ & $58.3 \pm 3.4$ & $57.8 \pm 3.0$ & $70.3 \pm 3.3$ \\
\hline
\end{tabular}

\subsection{Gel Permeation Chromatography (GPC)}

Pectin samples were analyzed through gel permeation chromatography to investigate molecular weights and differences in extraction conditions. For all purified samples, an evaluation of $\mathrm{dn} / \mathrm{dc}$ : a characteristic value for a sample-solvent-temperature combination, was performed in triplicate.

Data reported in Table 3 highlight a clear decrease in $M_{w}, M_{n}$, and IV with the increasing extraction time with an acetic acid concentration of $9 \%$, indicating that $\mathrm{pH}$ and extraction time play an important role in pectin structure and its final properties; however, pectin extracted with 3\% HAc for $6 \mathrm{~h}$ shows higher values of all parameters. By observing chromatograms at a refractive index (RI) detector of $9 \%$ HAc series (Figure 1a), it is possible to note that the increase in extraction time (2-6 h) leads to degradation of higher molecular weights (differences in the starting point of the curves in the $6.7-9.5 \mathrm{~mL}$ region) and an increase in the area in the 9.5-12 mL region, corresponding to the lower molecular weights-oligomeric fraction, together with other fractions present in citrus waste, such as polyphenol, flavonoids, and others. This behavior is also supported by chromatograms analyzed through a viscometer detector (Figure 1b), in which the decrease in viscosity emphasizes the degradation trend.

Table 3. Molecular weight parameters and intrinsic viscosity of extracted pectins vs. different processing times and acetic acid concentrations.

\begin{tabular}{cccc}
\hline Samples & $\mathbf{M}_{\mathbf{n}}$ (Da) & $\mathbf{M}_{\mathbf{w}}(\mathbf{D a})$ & $\mathbf{I V}$ \\
\hline PEC-2h-9\% & 55,503 & 140,719 & 1.53 \\
PEC-4h-9\% & 39,320 & 116,889 & 0.96 \\
PEC-6h-9\% & 25,443 & 91,293 & 0.57 \\
PEC-6h-3\% & 12,6486 & 308,847 & 1.69 \\
\hline
\end{tabular}

(a)

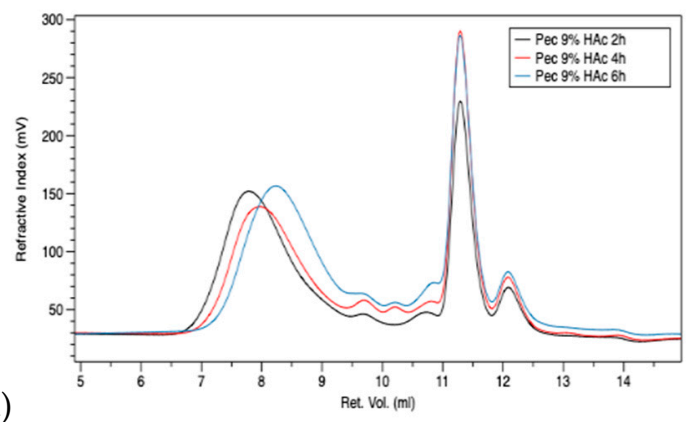

(b)

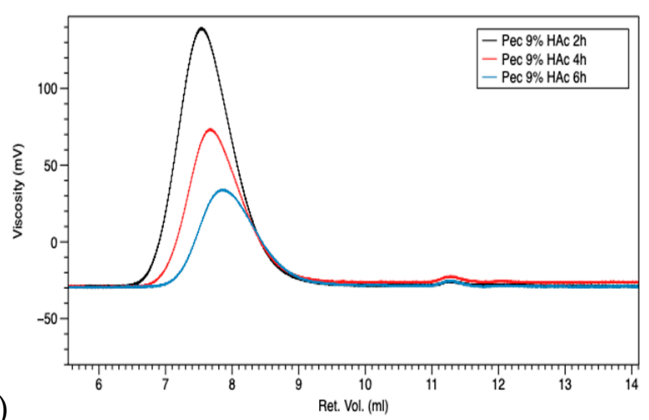

Figure 1. Refractive index (a) and viscometer (b) chromatograms of pectins at $9 \%$ HAc and different extraction times: $2 \mathrm{~h}$-black, $4 \mathrm{~h}$-red, $6 \mathrm{~h}$-blue.

Comparing this trend with PEC-6h-3\% (in Figure 2 it was indicated as PEC 3\%-HAc$6 \mathrm{~h}$ ), it is possible to observe that the polymeric peak is detected at a higher retention volume (higher molecular weights) for the PEC-2h-9\% (in Figures 1 and 2 it was indicated as PEC 9\%-HAc-2 h) sample. Comparing the area of the PEC-6h-3\% chromatogram in the 
9.4-12 retention volume range with the corresponding area of PEC-2h-9\%, we can note that in the last chromatogram, there is a big increase in a low molecular weight fraction, which accounts for the best mechanical performance of the pectin extracted with low HAc content. In fact, this low molecular weight fraction acts as a plasticizer in appropriate quantities to achieve the best mechanical properties.

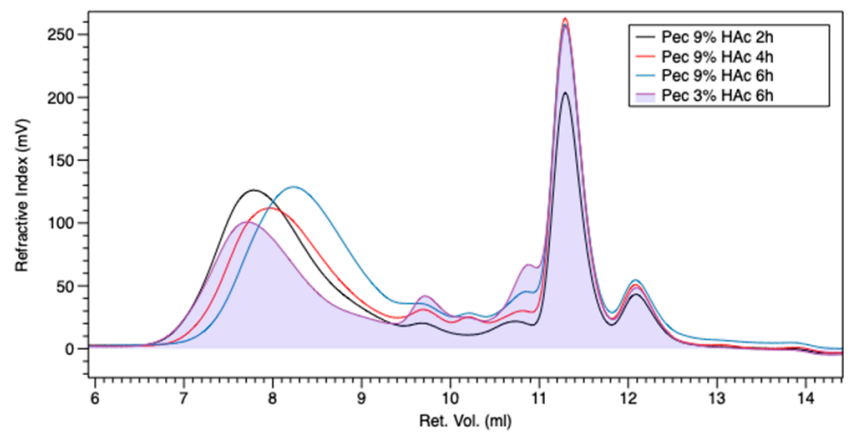

Figure 2. Refractive index detector chromatograms of pectins at 3-9\%-HAc and different extraction times: $2 \mathrm{~h}$-black, $4 \mathrm{~h}$-red, $6 \mathrm{~h}$-blue, and 3\%-HAc- $6 \mathrm{~h}$-violet.

\subsection{Attenuated Total Reflectance Fourier Transform Infrared (FTIR-ATR) Spectroscopy}

In Figure 3a, we present the FTIR spectra of pectin recovered after $6 \mathrm{~h}-3 \%(v / v)$ of HAc, purified pectin, and a FTIR spectrum of commercial citrus pectin. In general, for all pectins, it is possible to observe that the strong and wide peak at $3364 \mathrm{~cm}^{-1}$ was attributed to the $\mathrm{O}-\mathrm{H}$ elongation vibrations, and the $2936 \mathrm{~cm}^{-1}$ peak could be induced by the $\mathrm{C}-\mathrm{H}$ elongation vibrations of the $\mathrm{CH}_{2}$ and $\mathrm{CH}_{3}$ groups in the pectin. The absorption peaks shown at $1731 \mathrm{~cm}^{-1}$ and $1608 \mathrm{~cm}^{-1}$ were assigned to the $\mathrm{C}=\mathrm{O}$ stretch vibration of the methyl esterified carboxyl and to the asymmetric stretch vibration $\mathrm{C}=\mathrm{O}$ of the free carboxyl, respectively. The absorption bands at $1143 \mathrm{~cm}^{-1}$ and $1048 \mathrm{~cm}^{-1}$ corresponded to the stretching vibrations of the lateral groups $\mathrm{C}-\mathrm{OH}$ and to the vibration of the glyosidic bond $\mathrm{C}-\mathrm{O}-\mathrm{C}$ [46]. Figure 3a shows the FTIR-ATR spectra of the PEC-6h-3\%. In the region $3400-2500 \mathrm{~cm}^{-1}$, a wide absorption band is observed because of the stretching vibrations caused by intermolecular interactions through the $\mathrm{O}-\mathrm{H}$ bonds between the pectin monomers. The peak at around $2950 \mathrm{~cm}^{-1}$ refers to the $\mathrm{C}-\mathrm{H}$ vibrations of the methynic groups in the polymer chain and the methyl group of the methyl ester. These include the bending and stretching vibrations of $\mathrm{CH}, \mathrm{CH}_{2}$, and $\mathrm{CH}_{3}$ [47]. The peaks at $1760-1730$ and $1630-1600 \mathrm{~cm}^{-1}$ were due to the relative contribution of the ester carbonyl groups $(\mathrm{C}=\mathrm{O})$ and to the stretching of the carboxylate ions $\left(\mathrm{COO}^{-}\right)$, respectively [48]. The carboxylate groups show a weaker symmetrical stretch band near $1400 \mathrm{~cm}^{-1}$. In the pectin samples, the weakest $\mathrm{COO}^{-}$symmetric stretch is followed by moderately intense absorptions between 1300 and $800 \mathrm{~cm}^{-1}$, collectively defined as the region of the fingerprint that is unique for a compound. These bands are generally difficult to interpret. Other minor bands in pectin samples are $\mathrm{C}-\mathrm{H}$ bending and $\mathrm{C}-\mathrm{O}$ stretching occurring at $1380 \mathrm{~cm}^{-1}$ and $1300-1000 \mathrm{~cm}^{-1}$, respectively [49]. The absorption peaks at $1100-1040 \mathrm{~cm}^{-1}$ were assigned to the $\mathrm{C}-\mathrm{O}-\mathrm{C}$ stretch vibrations of the polymer chain structure [50]. In particular, it is possibly evidenced that in the spectrum of PEC- $6 \mathrm{~h}-3 \%$, a sharp absorption band is also observed between 1600 and $1500 \mathrm{~cm}^{-1}$ due to aromatic double bonds (aromatic rings) related to the presence of bioactive molecules (circled by the yellow circle), as indicated by the black arrow in Figure 3b. Moreover, at around $1520 \mathrm{~cm}^{-1}$, there is a new peak, indicating the functional group of the phenolic compound in the PEC-6h-3\% sample [51]. This confirms that simply washing the liquid extract with alcohols does not completely remove the polyphenols fraction. Moreover, the spectrum of purified pectin obtained is perfectly comparable with commercial citrus pectin. Thus, the purification treatment recovers a pectin that is very similar to commercial pectin, as shown from Figure 3a. 


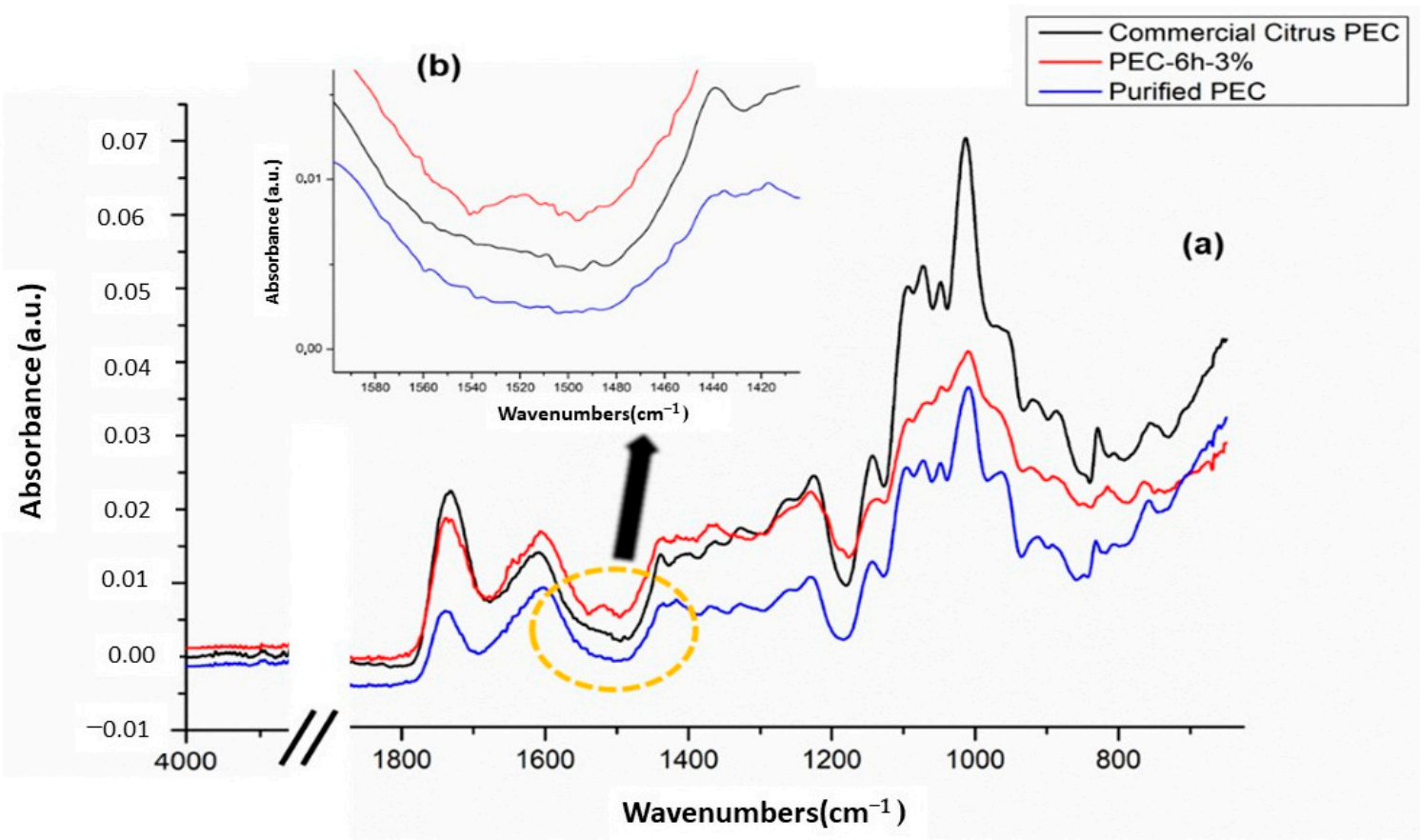

Figure 3. FTIR-ATR spectrum of all pectin samples (a) and the presence (b) of bioactive molecules peak.

On this basis, we performed the preliminarily evaluation of the fraction soluble in the hydro-alcoholic phase obtained during the purification of the PEC-6h-3\% sample. The recovery of dry mass, TPC, and TFC was assessed as $46 \% \mathrm{w}$ (with respect to the initial mass of the powder citrus waste), $46.34 \pm 2 \mathrm{mg} \mathrm{CE} / \mathrm{g}$, and $34.42 \mathrm{mg} \pm 3 \mathrm{CE} / \mathrm{g}$, respectively. Further studies are needed to investigate the antioxidant activity, composition, and other properties of pectin-enriched films for applications such as food-packaging smart materials with the aim of obtaining value-added products from bio-waste.

\subsection{Thermogravimetric Analysis (TGA)}

In Figure $4 a, b$, we present the TGA thermograms and their Derivative Thermogravimetry (DTG) of commercial citrus pectin, PEC-6h-3\%, and purified pectin. All curves were normalized with respect to the initial sample weights. The results of the thermogravimetric analyses are presented in Table 4 . The TGA curve records the weight loss of pectin during heating. First of all, from Figure $4 a, b$, it is possible to observe that the thermal degradation pattern of purified pectin is similar to that of commercial citrus pectin. This confirms that the extracted pectin, which was subsequently purified in a step-by-step process, is comparable to commercial citrus pectin.
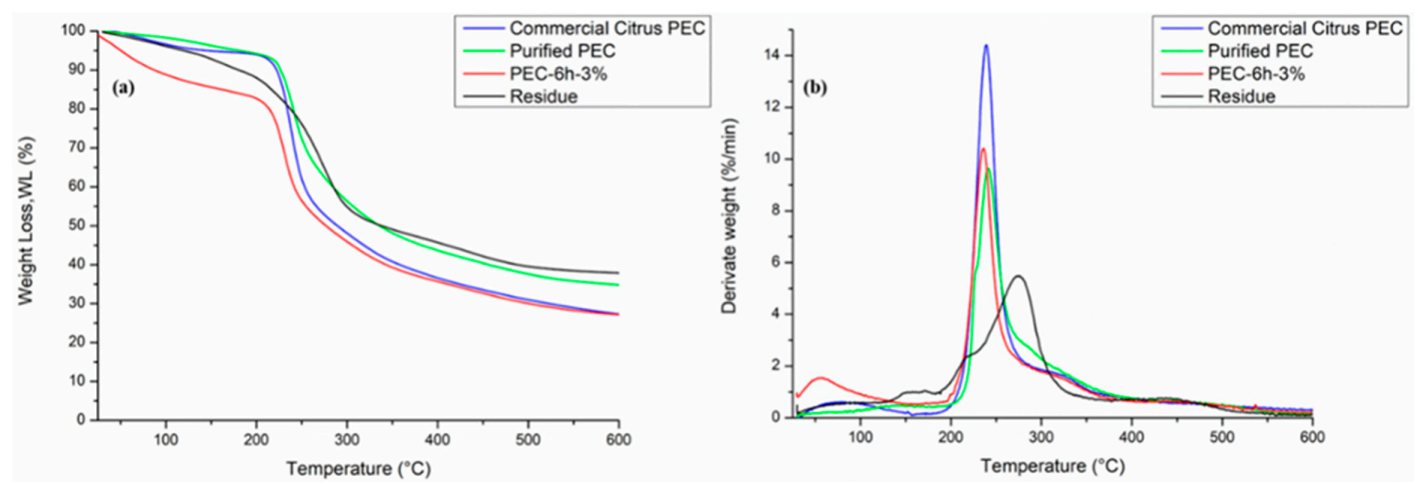

Figure 4. Thermogravimetric analysis (TGA) (a) and Derivative Thermogravimetry (DTG) (b) thermograms of all pectins and the lignocellulose residue solid. 
Table 4. Mechanical properties (tensile test) of Purified PEC and PEC films.

\begin{tabular}{cccc}
\hline Data/Samples & $\begin{array}{c}\text { Young Modulus (E) } \\
(\mathbf{M P a})\end{array}$ & $\begin{array}{c}\text { Tensile Strength }(\sigma) \\
(\mathbf{M P a})\end{array}$ & $\begin{array}{c}\text { Elongation at Break }(\varepsilon) \\
\mathbf{( \% )}\end{array}$ \\
\hline Purified PEC film & $4045.0 \pm 1051$ & $22.0 \pm 22$ & $0.7 \pm 0.4$ \\
PEC film & $46.0 \pm 33$ & $3.2 \pm 2$ & $31.2 \pm 9.3$ \\
\hline
\end{tabular}

The value of the force to breaking of the biofilms increases from PEC to PEC-25, as can be seen from Figure 5. For the PEC-35 biocomposite, it is possible to observe a decrease in the value of the force to breaking. Evidently, the presence of filler in an elevated amount induced a poor interfacial adhesion between the liquid matrix and the residue, which is also jointly responsible for the scarce mechanical stress transfer from the continuous to the dispersed phase.
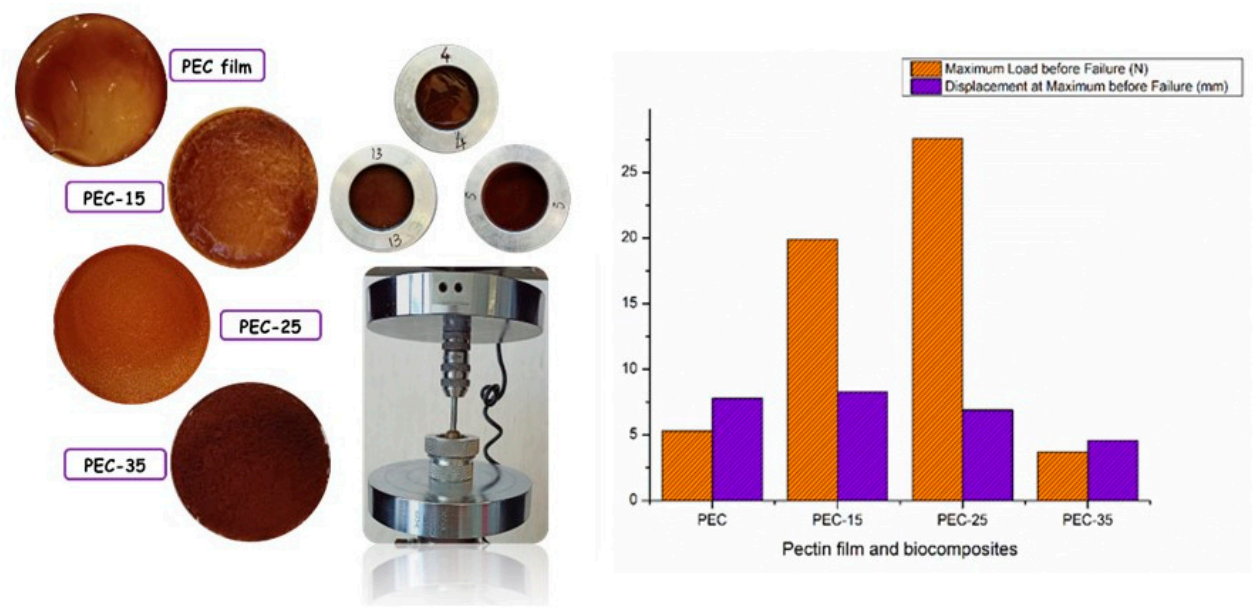

Figure 5. Puncture tests of the pectin film and biocomposites.

In our case, it was possible to observe that the thermogravimetric curves of the pectins (Figure 4a) principally presented two thermal steps: the first thermal step consisted of a weight loss of up to $10 \%$ in the $50-120^{\circ} \mathrm{C}$ range, which was related to the evaporation of the water present in the sample; the second thermal step started around $200{ }^{\circ} \mathrm{C}$. In this step, a rapid mass loss occurred, which was associated with the decomposition and depolymerization of pectin $(\sim 50 \%)$. The thermal degradation of the galacturonic acid chains caused the formation of various gaseous products $[52,53]$. The $\mathrm{T}_{\text {peak }}$ was determined in a range of $210-249{ }^{\circ} \mathrm{C}$ for all pectins. Moreover, in Figure $4 \mathrm{a}$, it is possible to observe the TGA curve of the lignocellulose residue. The weight loss of the residue mainly occurred in the temperature range of $50-600{ }^{\circ} \mathrm{C}$, which can be divided into three phases: $50-150{ }^{\circ} \mathrm{C}, 150-400{ }^{\circ} \mathrm{C}$, and $400-600{ }^{\circ} \mathrm{C}$ [54]. Weight loss in the first phase $\left(50-150{ }^{\circ} \mathrm{C}\right)$ was mainly caused by the evaporation of the absorbed water and the decomposition of low molecular weight polysaccharides. The second stage $\left(150-400^{\circ} \mathrm{C}\right)$ was mainly caused by the degradation of hemicellulose, lignin, pectin, etc. Third stage $\left(400-600^{\circ} \mathrm{C}\right)$ was slow, probably as a result of the decomposition of complex lignin polymeric compounds [55].

As regards the DTG curves of the pectins (Figure $4 \mathrm{~b}$ ), a mass variation was observed in a very small and wide peak, at a temperature of around $100{ }^{\circ} \mathrm{C}$, corresponding to the evaporation of water [56]. However, it was possible to note three flex points in the DTG curve of the PEC-6h-3\%. The first flex point occurs in an interval between $150-200{ }^{\circ} \mathrm{C}$ probably due to a polyphenol and sugar fraction still present in the pectin after washing with alcohols. The second flex point occurs in an interval between 210 and $249{ }^{\circ} \mathrm{C}$ due to the thermal degradation of the pectin. The third flex point, wider and less clear, can be observed at $300{ }^{\circ} \mathrm{C}$ and is probably due to the thermal degradation of the residual hemicellulose present in the pectin [57]. 
In DTG curves of commercial citrus PEC and purified PEC, one can note the presence of the peak related to bioactive molecules and the lignocellulose fraction. This confirms that the purification treatment of extracted pectin is necessary in order to obtain a pectin with a similar structure to that of commercial citrus pectin. In Figure $4 b$, the DTG curve of the pectin residue is shown. Moreover, in this case, a mass variation was observed in the DTG curve of the residue, evidenced by a very small and wide peak at a temperature of around $100{ }^{\circ} \mathrm{C}$, corresponding to the loss of water. In addition, two flex points were observed in the DTG curves. A first peak, more crowded and less clear, occurred at around $250{ }^{\circ} \mathrm{C}$ due to the thermal degradation of the hemicellulose fraction in the residues [58].

Finally, it was possible to note a clear and wide peak in a range between 300 and $400{ }^{\circ} \mathrm{C}$, caused by the thermal degradation of the lignocellulose fraction residue.

\subsection{Mechanical Tests: Tensile Test and Puncture Test}

The Mechanical properties of the pectin film and biocomposites are summarized in Tables 4 and 5. Young's modulus (E) specifies the stiffness or rigidity of the film, tensile strength $(\sigma)$ indicates the tensile strength of the film up to breaking, and elongation at break $(\varepsilon)$ describes the flexibility or extensibility of the films up to breaking. The results, reported in Table 4, show that the tensile strength and Young's modulus values of the purified pectin film are higher than those of the pectin film (PEC) obtained from the liquid extract, due to the higher molecular rigidity [27].

Table 5. Mechanical properties (puncture test) of the pectin film and biocomposites.

\begin{tabular}{ccc}
\hline Data/Samples & $\begin{array}{c}\text { Force to Break } \\
\mathbf{( N )}\end{array}$ & $\begin{array}{c}\text { Displacement } \\
\text { (mm) }\end{array}$ \\
\hline PEC & $5.3 \pm 1.8$ & $7.8 \pm 1.2$ \\
PEC-15 & $19.9 \pm 7.4$ & $8.3 \pm 0.7$ \\
PEC-25 & $27.6 \pm 7.9$ & $6.9 \pm 3.3$ \\
PEC-35 & $3.7 \pm 1.2$ & $4.6 \pm 0.5$ \\
\hline
\end{tabular}

However, the PEC film demonstrated a higher value of elongation at breaking as compared to the purified pectin film, due to the presence of bioactive molecules (flavonoids, flavanones, anthocyanins, phenolic acids, etc.) and essential oils that act as plasticizers, which are able to increase polysaccharide macromolecular chain mobility and caused a sharp decrease in the $\mathrm{E}$ and $\sigma$. Tensile strength and elongation at breaking were usually related to the network of the film microstructure and the intermolecular force between them [59].

The results of the puncture test for the PEC, PEC-15, PEC-25, and PEC-35 biocomposites are reported in Table 5. From the data analysis, it was possible to observe an increase in the resistance to breaking when lignocellulose residue (filler) was added in an amount equal to $0.25 \mathrm{~g}$ [60]. The force to breaking of the films depended on the thickness and component ratio of the films. The thicker the film and the higher the concentration of filler, the more resistant; thus, the greater the force at breaking point. However, an increase in filler content causes a slight decrease in displacement at breaking point. The deformation at breaking point is connected to the elasticity of films [61].

This outcome could be due to the increase in defects (i.e., kinks), typically an indicator of inhomogeneity and a random dispersion filler acting as points of stress concentration. On the other hand, as the amount of filler increased, it is possible to see a decrease in the displacement at breaking point for the PEC-25 and PEC-35 samples, typical of a more stiff and less elastic material, as show in Table 5.

\subsection{Scanning Electron Microscope (SEM)}

The SEM micrographs of PEC-6h-3\%, purified pectin, commercial citrus pectin, and residue are shown in Figure 6a-c. From the SEM image of the commercial citrus pectin (Figure 6a), the material was verified to be fibrous with compact aggregates, i.e., it had an irregular morphology [62]. The PEC-6h-3\% sample presented irregular intercellular 
spaces that were rough and uneven and compressed aspects (Figure 6c). In particular, it is possible to observe a few structural changes due to the treatment with acetic acid and water; thus, increasing the irregular porous surface structure and small particle size [63].
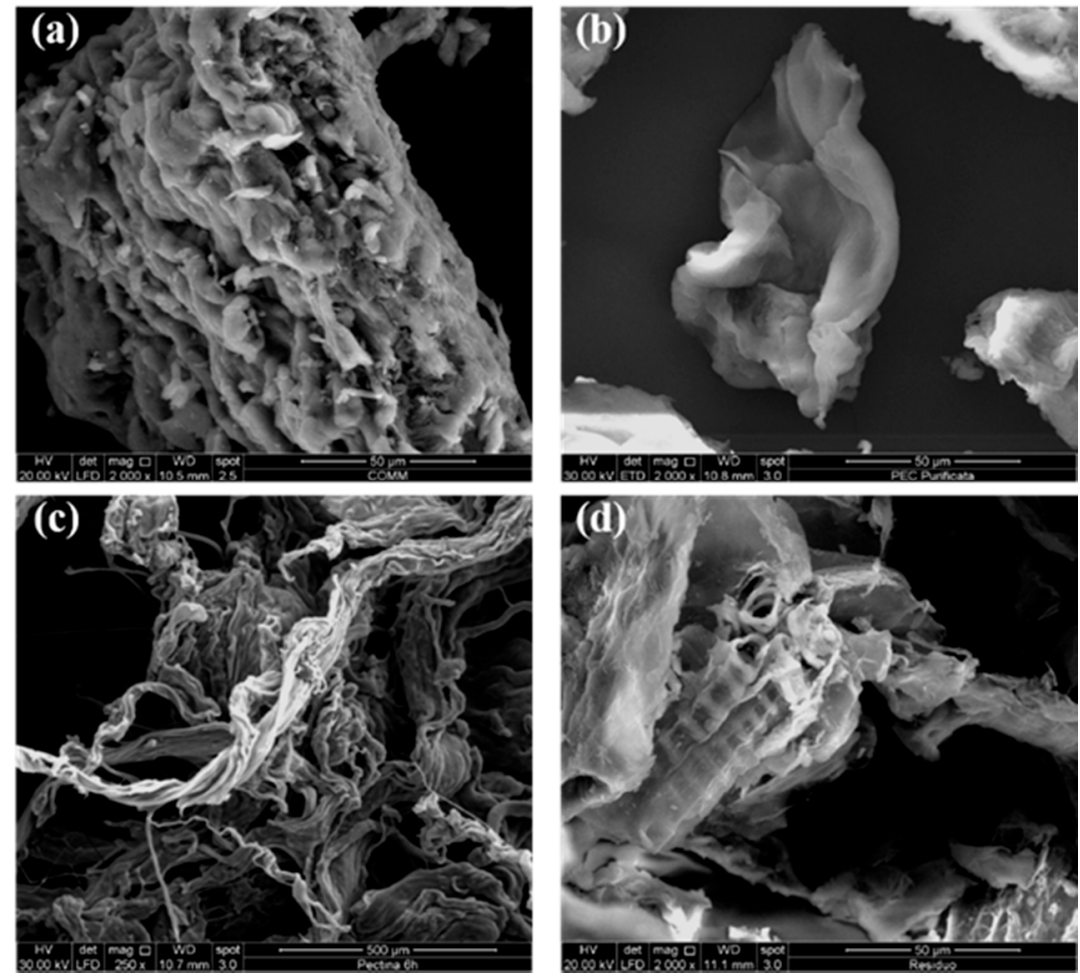

Figure 6. SEM micrographs of commercial pectin (a), purified PEC (b), PEC-6h-3\% (c), and residue (d).

From the analysis of SEM picture of the purified pectin (Figure 6b), it is noted that the morphological structure is similar to that of commercial citrus pectin. On the other hand, comparing the PEC-6h-3\% and purified pectin micrographs, a notable difference due to a presence of lignocellulose residues on the PEC-6h-3\% surface can be seen. Thus, it is possible to conclude that the purification and centrifugation treatments allow large fatsoluble and lignocellulose residue fractions to be removed, causing evident morphological changes [64].

Finally, in Figure 6d, the micrograph of the residue is shown. In the residue, compact and joined fibrous cellulose structures were observed, showing some alignment. Each elementary fiber also had a compact structure; exhibiting an alignment with some other nonfibrous components on the residual surface (Figure 6d) [65].

The effect of the acid treatment, which occurred during the extraction of pectin, leads to a greater presence of coarse and disordered fibers with clear cusps (spool) for the longer extraction times. As regards the residue obtained after $6 \mathrm{~h}$, it can be clearly seen in Figure $6 \mathrm{~d}$ that the fiber bundles contain a large number of fiber cells aligned and delimited by lignin and hemicellulose [66]. Moreover, in the Figure 6d, we can see a cellular network due caused by the presence of interwoven and jagged microfibrils and to the treatment with acetic acid, which has smoothed the fiber surface [67].

The cross-sectional images of the biocomposites are shown in Figure 7a-d; micrographs of the PEC and PEC-15 samples with a homogeneous surface are shown in Figure 7a,b. In particular, it is possible to observe that the lignocellulose residue solid, in the PEC-15, is completely covered by a polymeric matrix, allowing for a good distribution and interfacial adhesion [68]. PEC-25 and PEC-35 biocomposites demonstrated (Figure 7c,d) an intense formation of defects (i.e., kinks) on their surface, and in the cross-section, due to the presence higher amounts of residue. This confirms the observation made from the mechanical proper- 
ties, as discussed above. Thus, the filler (residue) causes a decrease in the displacement at the breaking point, resulting in breakage of the PEC-25 and PEC-35 samples and the formation of voids as a result of the removal of filler particles [69].
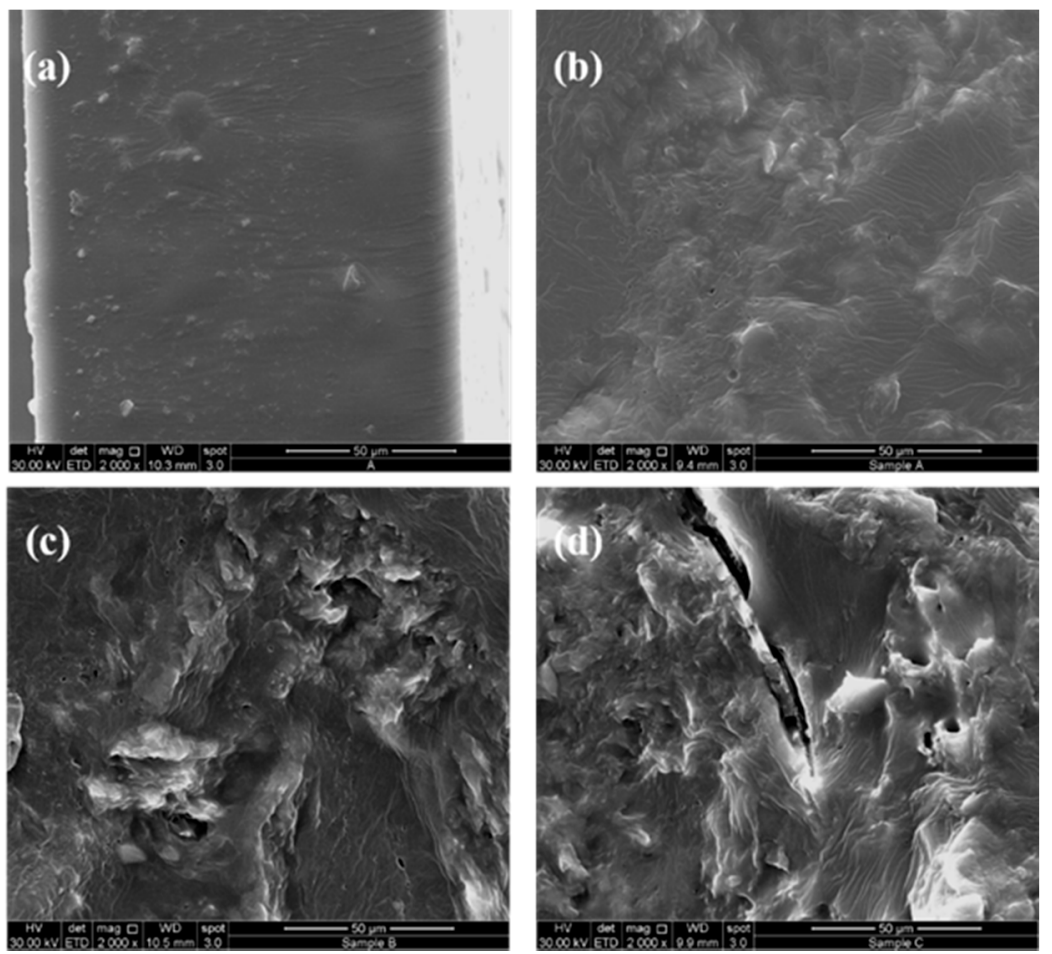

Figure 7. SEM micrographs of pectin film (a) and PEC-15 (b), PEC-25 (c), and PEC-35 (d) biocomposites.

For this reason, from Figure $7 \mathrm{c}, \mathrm{d}$, it is possible to note the presence of rough and smoothed zones typical of a material with poor interfacial adhesion between the polymeric matrix and filler.

\section{Conclusions}

In this paper, we present our study on the optimization of the extraction conditions of citrus pomace using a combination of time and the concentration of mild organic solvents, such as acetic acid, to recover high $\mathrm{M}_{\mathrm{w}}$ pectin. Full characterization of the obtained pectin and other organic components was carried out. The current global trend towards the efficient use of natural resources promotes sustainable agricultural production and the transformation of agricultural waste into high value-added products. Our preliminary study shows that the pomace itself and the biopolymers, such as pectin and cellulose, that can be obtained from this pomace have the potential to be used in the development of biocomposite membranes from aqueous acidic solutions, which can be utilized as agricultural mulching films. Finally, the bioactive molecules extracted from citrus pomace are currently the subject of an investigation related to their specific composition and functional activity. On the basis of the results, a biopolymer matrix will be assembled with the aim of producing bioactive food packaging materials. These studies will be the subject of a forthcoming paper.

Author Contributions: Conceptualization, B.I.; methodology, B.I. and M.M.; validation, G.D.P. and D.Z.; investigation, G.D.P. and D.Z.; data curation, D.Z.; writing—original draft preparation, D.Z.; writing - review and editing, B.I., G.S.; supervision, B.I., G.S.; funding acquisition, B.I. All authors have read and agreed to the published version of the manuscript. 
Funding: This research was funded by PRIN: Progetti di Ricerca di Interesse Nazionale-Bando 2017-GoodbyWaste: Obtain "GOOD products-exploit BY-products-reduce WASTE" Grant number COD. 2017JTNK78.

Institutional Review Board Statement: Not applicable.

Informed Consent Statement: Not applicable.

Data Availability Statement: Not applicable.

Acknowledgments: The authors acknowledge the grant PRIN: Progetti di Ricerca di Interesse Nazionale-Bando 2017-GoodbyWaste: Obtain "GOOD products-exploit BY-products-reduce WASTE" (COD. 2017JTNK78). The authors also thank Maria Cristina Del Barone, for her valid support in morphological analysis performed in (LAMeST) laboratory of the Institute for Polymers, Composites and Biomaterials, National Council of Research, Pozzuoli, Italy.

Conflicts of Interest: The authors declare no conflict of interest.

\section{References}

1. Castro, M.D.L.D. Towards a Comprehensive Exploitation of Agrofood Residues: Olive Tree-Olive Oil as Example. Comptes Rendus Chim. 2014, 17, 252-260. [CrossRef]

2. Desai, B.H.; Gavouneli, M.; Koivurova, T. From the Editors-in-Chief. Yearb. Int. Environ. Law 2017, 28, xi-xii. [CrossRef]

3. Dao, T.A.T.; Webb, H.K.; Malherbe, F. Optimization of Pectin Extraction from Fruit Peels by Response Surface Method: Conventional versus Microwave-Assisted Heating. Food Hydrocoll. 2021, 113, 106475. [CrossRef]

4. De Albuquerque, M.A.C.; Levit, R.; Beres, C.; Bedani, R.; de Moreno, M.A.; Isay Saad, S.M.; Leblanc, J.G.J. Tropical Fruit By-Products Water Extracts of Tropical Fruit by-Products as Sources of Soluble Fibres and Phenolic Compounds with Potential Antioxidant, Anti-Inflammatory, and Functional Properties. J. Funct. Foods 2019, 52, 724-733. [CrossRef]

5. Jiang, B.; Wang, X.; Wang, L.; Wu, S.; Li, D.; Liu, C.; Feng, Z. Fabrication and Characterization of a Microemulsion Stabilized by Integrated Phosvitin and Gallic Acid. J. Agric. Food Chem. 2020, 68, 5437-5447. [CrossRef] [PubMed]

6. Jiang, B.; Wang, M.; Wang, X.; Wu, S.; Li, D.; Liu, C.; Feng, Z.; Li, J. Effective Separation of Prolyl Endopeptidase from Aspergillus Niger by Aqueous Two Phase System and Its Characterization and Application. Int. J. Biol. Macromol. 2021, 169, 384-395. [CrossRef] [PubMed]

7. Jiang, B.; Na, J.; Wang, L.; Li, D.; Liu, C.; Feng, Z. Reutilization of Food Waste: One-Step Extration, Purification and Characterization of Ovalbumin from Salted Egg White by Aqueous Two-Phase Flotation. Foods 2019, 8, 286. [CrossRef] [PubMed]

8. Sharma, K.; Mahato, N.; Lee, Y.R. Extraction, Characterization and Biological Activity of Citrus Flavonoids. Rev. Chem. Eng. 2019, 35, 265-284. [CrossRef]

9. Ke, Z.; Xu, X.; Nie, C.; Zhou, Z. Citrus Flavonoids and Human Cancers. J. Food Nutr. Res. 2015, 3, 341-351. [CrossRef]

10. Benavente-García, O.; Castillo, J.; Marin, F.R.; Ortuño, A.; Del Río, J.A. Uses and Properties of Citrus Flavonoids. Am. Chem. Soc. 1997, 45, 4505-4515.

11. Jandrić, Z.; Islam, M.; Singh, D.K.; Cannavan, A. Authentication of Indian Citrus Fruit/Fruit Juices by Untargeted and Targeted Metabolomics. Food Control 2017, 72, 181-188. [CrossRef]

12. Miller, E.V.; Winston, J.R.; Schomer, H.A. Physiological Studies of Plastid Pigments in Rinds of Maturing Oranges. J. Agric. Res. 1940, 60, 259-267.

13. Chen, X.M.; Tait, A.R.; Kitts, D.D. Flavonoid Composition of Orange Peel and Its Association with Antioxidant and AntiInflammatory Activities. Food Chem. 2017, 218, 15-21. [CrossRef]

14. Chavan, P.; Singh, A.K.; Kaur, G. Recent Progress in the Utilization of Industrial Waste and By-products of Citrus Fruits: A Review. J. Food Process Eng. 2018, 41, e12895. [CrossRef]

15. Schmidt, U.S.; Pietsch, V.L.; Rentschler, C.; Kurz, T.; Endreß, H.U.; Schuchmann, H.P. Influence of the Degree of Esterification on the Emulsifying Performance of Conjugates Formed between Whey Protein Isolate and Citrus Pectin. Food Hydrocoll. 2016, 56,1-8. [CrossRef]

16. Willats, W.G.T.; Knox, J.P.; Mikkelsen, J.D. Pectin: New Insights into an Old Polymer Are Starting to Gel. Trends Food Sci. Technol. 2006, 17, 97-104. [CrossRef]

17. Caffall, K.H.; Mohnen, D. The Structure, Function, and Biosynthesis of Plant Cell Wall Pectic Polysaccharides. Carbohydr. Res. 2009, 344, 1879-1900. [CrossRef]

18. Yapo, B.M. Rhamnogalacturonan-I: A Structurally Puzzling and Functionally Versatile Polysaccharide from Plant Cell Walls and Mucilages; Taylor \& Francis Group: Abingdon, UK, 2011; Volume 51.

19. Marić, M.; Grassino, A.N.; Zhu, Z.; Barba, F.J.; Brnčić, M.; Rimac Brnčić, S. An Overview of the Traditional and Innovative Approaches for Pectin Extraction from Plant Food Wastes and By-Products: Ultrasound-, Microwaves-, and Enzyme-Assisted Extraction. Trends Food Sci. Technol. 2018, 76, 28-37. [CrossRef]

20. O'Neill, M.A.; Ishii, T.; Albersheim, P.; Darvill, A.G. RHAMNOGALACTURONAN II: Structure and Function of a Borate Cross-Linked Cell Wall Pectic Polysaccharide. Annu. Rev. Plant Biol. 2004, 55, 109-139. [CrossRef] 
21. Oosterveld, A.; Beldman, G.; Schols, H.A.; Voragen, A.G.J. Arabinose and Ferulic Acid Rich Pectic Polysaccharides Extracted from Sugar Beet Pulp. Carbohydr. Res. 1996, 288, 143-153. [CrossRef]

22. Ridley, B.L.; O'Neill, M.A.; Mohnen, D. Pectins: Structure, Biosynthesis, and Oligogalacturonide-Related Signaling. Phytochemistry 2001, 57, 929-967. [CrossRef]

23. Pellerin, P.; O'Neill, M.A. The Interaction of the Pectic Polysaccharide Rhamnogalacturonan II with Heavy Metals and Lanthanides in Wines and Fruit Juices. Analusis 1998, 26, 32-36. [CrossRef]

24. Mohnen, D. Pectin Structure and Biosynthesis. Curr. Opin. Plant Biol. 2008, 11, 266-277. [CrossRef] [PubMed]

25. Yang, J.S.; Mu, T.H.; Ma, M.M. Extraction, Structure, and Emulsifying Properties of Pectin from Potato Pulp. Food Chem. 2018, 244, 197-205. [CrossRef] [PubMed]

26. Šešlija, S.; Nešić, A.; Ružić, J.; Kalagasidis Krušić, M.; Veličković, S.; Avolio, R.; Santagata, G.; Malinconico, M. Edible Blend Films of Pectin and Poly (Ethylene Glycol): Preparation and Physico-Chemical Evaluation. Food Hydrocoll. 2018, 77, 494-501. [CrossRef]

27. Nešić, A.; Onjia, A.; Davidović, S.; Dimitrijević, S.; Errico, M.E.; Santagata, G.; Malinconico, M. Design of Pectin-Sodium Alginate Based Films for Potential Healthcare Application: Study of Chemico-Physical Interactions between the Components of Films and Assessment of Their Antimicrobial Activity. Carbohydr. Polym. 2017, 157, 981-990. [CrossRef]

28. Chua, B.L.; Tang, S.F.; Ali, A.; Chow, Y.H. Optimisation of Pectin Production from Dragon Fruit Peels Waste: Drying, Extraction and Characterisation Studies. SN Appl. Sci. 2020, 2. [CrossRef]

29. Seixas, F.L.; Fukuda, D.L.; Turbiani, F.R.B.; Garcia, P.S.; de, O. Petkowicz, C.L.; Jagadevan, S.; Gimenes, M.L. Extraction of Pectin from Passion Fruit Peel (Passiflora Edulis f.Flavicarpa) by Microwave-Induced Heating. Food Hydrocoll. 2014, 38, 186-192. [CrossRef]

30. Sayah, M.Y.; Chabir, R.; Benyahia, H.; Rodi, K.Y.; Ouazzani, C.F.; Touzani, H.; Errachidi, F. Yield, Esterification Degree and Molecular Weight Evaluation of Pectins Isolated from Orange and Grapefruit Peels under Different Conditions. PLoS ONE 2016, 11, e0161751. [CrossRef]

31. Immirzi, B.; Santagata, G.; Vox, G.; Schettini, E. Preparation, Characterisation and Field-Testing of a Biodegradable Sodium Alginate-Based Spray Mulch. Biosyst. Eng. 2009, 102, 461-472. [CrossRef]

32. Kang, S.-M.; Bilal, S.; Shahzad, R.; Kim, Y.-N.; Park, C.-W.; Lee, K.-E.; Lee, J.-R.; Lee, I.-J. Effect of Ammonia and Indole-3-Acetic Acid Producing Endophytic Klebsiella Pneumoniae YNA12 as a Bio-Herbicide for Weed Inhibition: Special Reference with Evening Primroses. Plants 2020, 9, 761. [CrossRef]

33. Orzali, L. Chitosan in Agriculture: A New Challenge for Managing Plant Disease. In Biological Activities and Application of Marine Polysaccharides; Corsi, B., Ed.; IntechOpen: Rijeka, Croatia, 2017; pp. 17-36. ISBN 978-953-51-2860-1.

34. Giaccone, M.; Cirillo, C.; Scognamiglio, P.; Teobaldelli, M.; Mataffo, A.; Stinca, A.; Pannico, A.; Immirzi, B.; Santagata, G.; Malinconico, M.; et al. Biodegradable Mulching Spray for Weed Control in the Cultivation of Containerized Ornamental Shrubs. Chem. Biol. Technol. Agric. 2018, 5, 21. [CrossRef]

35. Vox, G.; Santagata, G.; Malinconico, M.; Immirzi, B.; Scarascia Mugnozza, G.; Schettini, E. Biodegradable Films and Spray Coatings as Eco-Friendly Alternative to Petro-Chemical Derived Mulching Films. J. Agric. Eng. 2013, 44. [CrossRef]

36. Winans, K.; Kendall, A.; Deng, H. The History and Current Applications of the Circular Economy Concept. Renew. Sustain. Energy Rev. 2017, 68, 825-833. [CrossRef]

37. Twinomuhwezi, H.; Godswill, A.C.; Kahunde, D. Extraction and Characterization of Pectin from Orange (Citrus Sinensis), Lemon (Citrus Limon) and Tangerine (Citrus Tangerina). Am. J. Phys. Sci. 2020, 1, 17-30.

38. Fakayode, O.A.; Abobi, K.E. Optimization of Oil and Pectin Extraction from Orange (Citrus Sinensis) Peels: A Response Surface Approach. J. Anal. Sci. Technol. 2018, 9, 20. [CrossRef]

39. Asgari, K.; Labbafi, M.; Khodaiyan, F.; Kazemi, M.; Hosseini, S.S. High-Methylated Pectin from Walnut Processing Wastes as a Potential Resource: Ultrasound Assisted Extraction and Physicochemical, Structural and Functional Analysis. Int. J. Biol. Macromol. 2020, 152, 1274-1282. [CrossRef] [PubMed]

40. Dewanto, V.; Wu, X.; Adom, K.K.; Hai Liu, R. Thermal Processing Enhances the Nutritional Value of Tomatoes by Increasing Total Antioxidant Activity. J. Agric. Food Chem. 2002, 50, 3010-3014. [CrossRef] [PubMed]

41. Papoutsis, K.; Pristijono, P.; Golding, J.B.; Stathopoulos, C.E.; Bowyer, M.C.; Scarlett, C.J.; Vuong, Q.V. Optimizing a Sustainable Ultrasound-Assisted Extraction Method for the Recovery of Polyphenols from Lemon by-Products: Comparison with Hot Water and Organic Solvent Extractions. Eur. Food Res. Technol. 2018, 244, 1353-1365. [CrossRef]

42. Malinconico, M.; Immirzi, B.; Schettini, E.; Vox, G.; Santagata, G.; Scarascia Mugnozza, G. An Overview on Innovative Biodegradable Materials for Agricultural Applications. In Progress in Polymer Degradation and Stability Research; Nova Science Publishers: New York, NY, USA, 2008; ISBN 978-1-60021-828-6.

43. Kuuva, T.; Lantto, R.; Reinikainen, T.; Buchert, J.; Autio, K. Rheological Properties of Laccase-Induced Sugar Beet Pectin Gels. Food Hydrocoll. 2003, 17, 679-684. [CrossRef]

44. Diaz, J.V.; Anthon, G.E.; Barrett, D.M. Nonenzymatic Degradation of Citrus Pectin and Pectate during Prolonged Heating: Effects of PH, Temperature, and Degree of Methyl Esterification. J. Agric. Food Chem. 2007, 55, 5131-5136. [CrossRef] [PubMed]

45. Fraeye, I.; De Roeck, A.; Duvetter, T.; Verlent, I.; Hendrickx, M.; Van Loey, A. Influence of Pectin Properties and Processing Conditions on Thermal Pectin Degradation. Food Chem. 2007, 105, 555-563. [CrossRef]

46. Jiang, Y.; Xu, Y.; Li, F.; Li, D.; Huang, Q. Pectin Extracted from Persimmon Peel: A Physicochemical Characterization and Emulsifying Properties Evaluation. Food Hydrocoll. 2020, 101, 105561. [CrossRef] 
47. Nisar, T.; Wang, Z.C.; Yang, X.; Tian, Y.; Iqbal, M.; Guo, Y. Characterization of Citrus Pectin Films Integrated with Clove Bud Essential Oil: Physical, Thermal, Barrier, Antioxidant and Antibacterial Properties. Int. J. Biol. Macromol. 2018, 106, 670-680. [CrossRef] [PubMed]

48. Singthong, J.; Cui, S.W.; Ningsanond, S.; Douglas Goff, H. Structural Characterization, Degree of Esterification and Some Gelling Properties of Krueo Ma Noy (Cissampelos Pareira) Pectin. Carbohydr. Polym. 2004, 58, 391-400. [CrossRef]

49. Gnanasambandam, R.; Proctor, A. Determination of Pectin Degree of Esterification by Diffuse Reflectance Fourier Transform Infrared Spectroscopy. Food Chem. 2000, 68, 327-332. [CrossRef]

50. Baron, R.D.; Pérez, L.L.; Salcedo, J.M.; Córdoba, L.P.; do Amaral, S.P.J. Production and Characterization of Films Based on Blends of Chitosan from Blue Crab (Callinectes Sapidus) Waste and Pectin from Orange (Citrus Sinensis Osbeck) Peel. Int. J. Biol. Macromol. 2017, 98, 676-683. [CrossRef] [PubMed]

51. Nisar, T.; Wang, Z.-C.; Alim, A.; Iqbal, M.; Yang, X.; Sun, L.; Guo, Y. Citrus Pectin Films Enriched with Thinned Young Apple Polyphenols for Potential Use as Bio-Based Active Packaging. CyTA 2019, 17, 695-705. [CrossRef]

52. Ghaffari, A.; Navaee, K.; Oskoui, M.; Bayati, K.; Rafiee-Tehrani, M. Preparation and Characterization of Free Mixed-Film of Pectin/Chitosan/Eudragit ${ }^{\circledR}$ RS Intended for Sigmoidal Drug Delivery. Eur. J. Pharm. Biopharm. 2007, 67, 175-186. [CrossRef]

53. Einhorn-Stoll, U.; Kunzek, H.; Dongowski, G. Thermal Analysis of Chemically and Mechanically Modified Pectins. Food Hydrocoll. 2007, 21, 1101-1112. [CrossRef]

54. Wang, W.; Ma, X.; Jiang, P.; Hu, L.; Zhi, Z.; Chen, J.; Ding, T.; Ye, X.; Liu, D. Characterization of Pectin from Grapefruit Peel: A Comparison of Ultrasound-Assisted and Conventional Heating Extractions. Food Hydrocoll. 2016, 61, 730-739. [CrossRef]

55. Zhang, Y.; Qi, J.; Zeng, W.; Huang, Y.; Yang, X. Properties of Dietary Fiber from Citrus Obtained through Alkaline Hydrogen Peroxide Treatment and Homogenization Treatment. Food Chem. 2020, 311, 125873. [CrossRef] [PubMed]

56. Hu, W.; Ye, X.; Chantapakul, T.; Chen, S.; Zheng, J. Manosonication Extraction of RG-I Pectic Polysaccharides from Citrus Waste: Optimization and Kinetics Analysis. Carbohydr. Polym. 2020, 235, 115982. [CrossRef]

57. Qin, Z.; Liu, H.M.; Cheng, X.C.; Wang, X.D. Effect of Drying Pretreatment Methods on Structure and Properties of Pectins Extracted from Chinese Quince Fruit. Int. J. Biol. Macromol. 2019, 137, 801-808. [CrossRef] [PubMed]

58. Tanaka, M.; Takamizu, A.; Hoshino, M.; Sasaki, M.; Goto, M. Extraction of Dietary Fiber from Citrus Junos Peel with Subcritical Water. Food Bioprod. Process. 2012, 90, 180-186. [CrossRef]

59. Cabello, P.S.D.; Takara, E.A.; Marchese, J.; Ochoa, N.A. Influence of Plasticizers in Pectin Films: Microstructural Changes. Mater. Chem. Phys. 2015, 162, 491-497. [CrossRef]

60. Schettini, E.; Santagata, G.; Malinconico, M.; Immirzi, B.; Mugnozza, G.S.; Vox, G. Recycled Wastes of Tomato and Hemp Fibres for Biodegradable Pots: Physico-Chemical Characterization and Field Performance. Resour. Conserv. Recycl. 2013, 70, 9-19. [CrossRef]

61. Nešić, A.; Ružić, J.; Gordić, M.; Ostojić, S.; Micić, D.; Onjia, A. Pectin-Polyvinylpyrrolidone Films: A Sustainable Approach to the Development of Biobased Packaging Materials. Compos. Part B 2017, 110, 56-61. [CrossRef]

62. Dalpasquale, M.; Mariani, F.Q.; Müller, M.; Anaissi, F.J. Citrus Pectin as a Template for Synthesis of Colorful Aluminates. Dye. Pigment. 2016, 125, 124-131. [CrossRef]

63. Tovar, A.K.; Godínez, L.A.; Espejel, F.; Ramírez-Zamora, R.M.; Robles, I. Optimization of the Integral Valorization Process for Orange Peel Waste Using a Design of Experiments Approach: Production of High-Quality Pectin and Activated Carbon. Waste Manag. 2019, 85, 202-213. [CrossRef] [PubMed]

64. Peng, J.; Abomohra, A.E.F.; Elsayed, M.; Zhang, X.; Fan, Q.; Ai, P. Compositional Changes of Rice Straw Fibers after Pretreatment with Diluted Acetic Acid: Towards Enhanced Biomethane Production. J. Clean. Prod. 2019, 230, 775-782. [CrossRef]

65. Naz, S.; Ahmad, N.; Akhtar, J.; Ahmad, N.M.; Ali, A.; Zia, M. Management of Citrus Waste by Switching in the Production of Nanocellulose. IET Nanobiotech. 2016, 10, 395-399. [CrossRef] [PubMed]

66. Belouadah, Z.; Ati, A.; Rokbi, M. Characterization of New Natural Cellulosic Fiber from Lygeum Spartum L. Carbohydr. Polym. 2015, 134, 429-437. [CrossRef] [PubMed]

67. Zafeiropoulos, N.E.; Williams, D.R.; Baillie, C.A.; Matthews, F.L. Engineering and Characterisation of the Interface in Flax Fibre/Polypropylene Composite Materials. Part I. Development and Investigation of Surface Treatments. Compos. Part A 2002, 33, 1083-1093. [CrossRef]

68. Lopes, I.A.; Santos, J., Jr.; Da Silva, D.C.; Da Silva, L.J.S.; Barros, A.K.; Villa-Vélez, H.A.; Santana, A.A. Characterization of Pectin Biofilms with the Addition of Babassu Mesocarp and Whey Protein Concentrate. Am. J. Mater. Sci. 2017, 7, 64-70. [CrossRef]

69. Bátori, V.; Jabbari, M.; Åkesson, D.; Lennartsson, P.R.; Taherzadeh, M.J.; Zamani, A. Production of Pectin-Cellulose Biofilms: A New Approach for Citrus Waste Recycling. Int. J. Polym. Sci. 2017, 2017. [CrossRef] 